\title{
The Financial Transparency Dynamics and Some Proposals on the Matter of Transparency Problem aimed at Developing Countries
}

\author{
A. Niyazi Özker \\ Assoc. Prof. Dr., Public Finance Department, \\ Faculty of Economic and Business Administration, \\ Bandirma Onyedi Eylul University - 10200\TURKEY
}

\begin{abstract}
In the study, we aimed to present some public budgetary dynamics that would have an impact on structural options in order to address some key structural issues such like transparency in particular developing countries with significant public deficits in the OECD. Transparency, as a financial phenomenon including to place in the objective of the budgeting, is to express the negative financial practices process that cause financial deviations for especially developing countries. Along with being monitored that some financial deflections related to financial transparency are inevitably appeared even after the developed financial formation process appearing from previous years to the current days. Namely, some measures and recommendations to transparency for especially developing countries in OECD countries to prevent central government budget deviations in practices are rather need to some more today's recommendations toward to both budget harmonization and optimal budget balances to present a comprehensive, accurate and reliable account of the public finances. It appears that this recommendations process mean also to identify, assess and manage prudently longer-term sustainability and other fiscal risks. It is understood that this recommendations process in the public budget process are rather meaningful also to identify, assess and manage prudently longer-term sustainability and other fiscal risks due to the fiscal plans and budgetary implementation through rigorous in the Central Budget Authority (CBE).
\end{abstract}

Keywords: Central Budget Authority (CBE); Central Government Budget Deviations; Public Budget Dynamics; OECD Countries; Financial Transparency.

JEL Codes: E61; E62; H61; H62; H68;

\section{INTRODUCTION}

The objective of fiscal transparency in the scope of government budget applications is that put forth all the financial relations that use together with the financial budget dynamics, as a whole, in the base of given accountability. Therefore, the dynamics that are related to transparency in the budget application process are not only meaningful in the practice process, but also contain the financial harmonization dynamics for OECD countries to ensure the aimed economic cooperation in the evaluation process. But, especially in developing countries some deviations from financial transparency come ability to a halt these practices and this phenomenon may be negative effect on the economic cooperation relations to constitute the associated financial programs like customs union. There have been currently the studies put forth by some public economists that are related to this financial phenomenon have been take place in the produced solutions aiming get over this negative financial deviation. Certainly, these are more that OECD has developed, and is developing, more detailed principles and recommendations for a further positive budget harmonization on specific elements of the overall budgeting framework. Alt and Lassen (2003) determined some fiscal transparency elements for OECD countries that can be considered as some recommendations in order to constitute the associated financial politics. Alt and Lassen (2003) attract attentions some 
critique financial practice essentials in their own studies, which can support any budget applications meaningfully for especially developing countries.

And also, it can be added that the study of Benito and Bastida (2009) as related to the transparency fact especially developing countries in OECD countries, which study contributed fiscal transparency application process in the base of fiscal imbalance and intense transparency-fiscal surplus. And also according to Benito Bastida (2009) the lack of financial transparency in the developing countries is connected to occur both the bureaucratic behavior and insufficient budget applications. The other element which effect negatively on the financial transparency is that politic rules interfere in budget rules or lies inside in each other directed towards the complicated financial formation in the same process. The expectations from transparency process should ensure the financial harmonization components that put forth the structural alterations to the radical features (Arnold, 2011). And also, these expectations have to ensure a reliable recorded system for financial operations that need to be observed clearly aimed at ensuring a healthy financial mechanism. In this respect, financial transparency is not only a phenomenon of monitoring financial transactions, but it is also a key in a radically targeted period. Therefore, OECD has taken an important role that play a leading role in the international community in promoting budget transparency including developing countries' budgets (OECD, 2015). It appears that especially, public budget dynamics are meaningful financial instruments in practices for Budget Transparency. These expectations from the considered public budget dynamics should be put forth some proposal aimed at integration on the framework of transparency (Bird, 2011). Because, the publicly experiences of recent years have emphasized that an optimal public budgeting should be supported by the various financial formation dynamics pillars of modern public governance (Chen, 2006).

\section{PUBLIC BUDGET'S TRANSPARENCY PROBLEM AND ITS ALTERATION DYNAMICS}

Modern public budgets, firstly, have to contain alternative alteration dynamics that also express financial transparency dynamics as a component of global integration process aimed at the desired inspections. As emphasized on before, an optimal public budgeting that contain transparency proposal of a modern public budget governance should be supported by the various financial formation dynamics (Carolan, 2016). These financial facts can be emphasized, as some main structural alterations terms, in that is accountability directed to ensure transparency including operational openness. But, certainly these are not sufficient to ensure a financial transparency, and participation in public budget process, and a strategic approach to planning that contain some financial advances aimed at achieving national objectives (Carolan, 2016). And also, public budget management has to be ability to comprehensive budget accounting with effective budget executions, which mean to put forth fiscal risk and sustainability in budgeting in fiscal objectives (Williamson and Eisen, 2016). It is not possible consider that all these budget components can be thought separate from each other. Namely, if financial transparency is an important objective especially global financial reliability, public budgets have to be in clear, predictable and credible limits that can take on some financial alteration risks related to ensure the fiscal management policy aimed at global integration for OECD countries (OECD, 2014). This structural financial performance ensures that make simpler financial operation evaluations, and put forth a meaningful ground for the value for national money are integral to the budget process especially for countries that aim financial innovations in the scope of OECD (OECD, 2014). But even so, it should be emphasized that independent audit on fiscal plans and budgetary implementations with condition the structural alterations are main spine related to transparency phenomenon. In the following figure 1 , we can see the relationship between the dynamics of structural units developed under the OECD on transparency. 


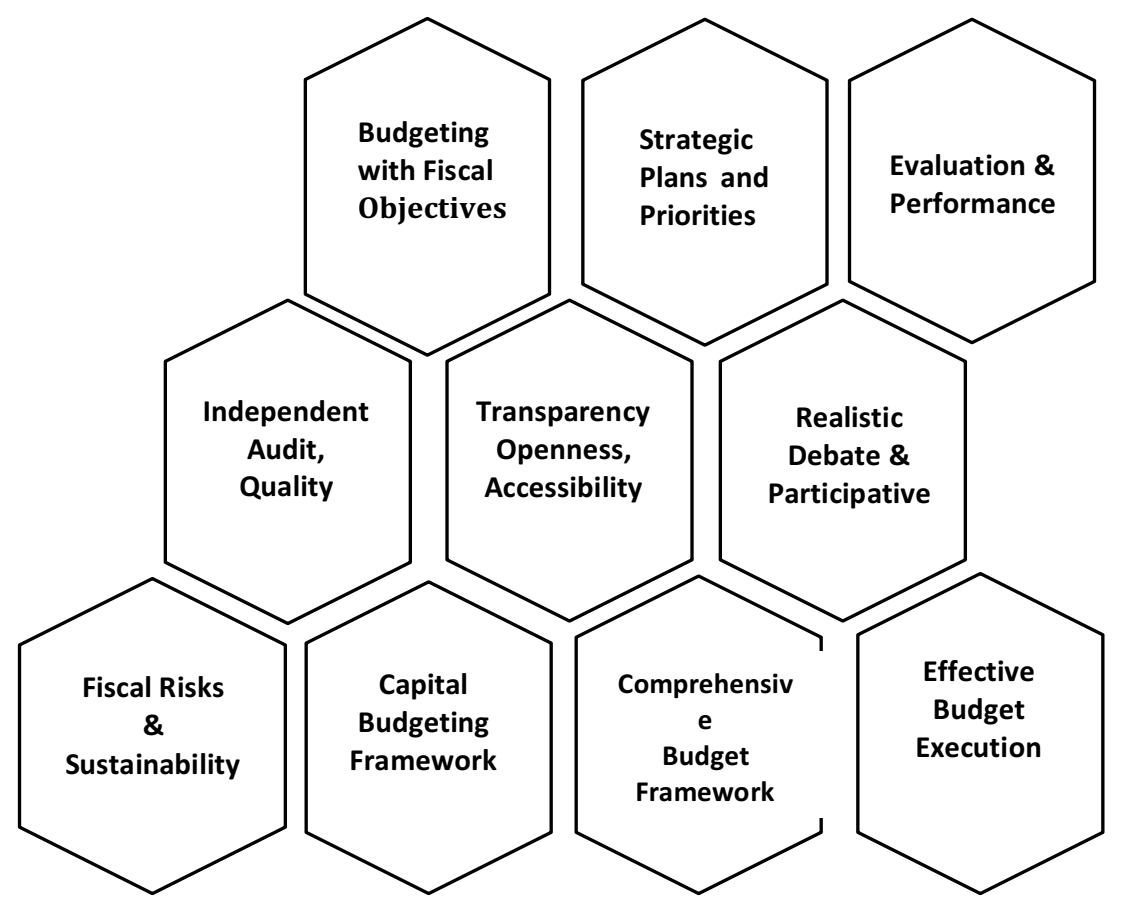

Source: OECD, Recommendation of The Council on Budgetary Governance, 2015.

Figure 1. The Alterations Dynamics of Public Budget related to Transparency Process

Modern public budgets, first, have to contain alternative alteration dynamics that also express financial transparency dynamics as a piece global integration process such as independent fiscal management with audit, integrity in the scope of the strategic plans. Certainly, these priorities are the corner stones of transparency facts in the framework of public budgets, which mean the alteration dynamics (Folscher and Renzio, 2017). In this stage, budget objectives and its evaluation and performance should be in harmonization as fiscal aims, thus can affect transparency indications. Furthermore, weak fiscal institutions that are associated with fiscal applications are often supported via legal regulations and sanctions.

It can be said that the concerned sanctions are insufficient directed towards transparency in the budget process because of which is a lack of strength application tool for scale discipline in terms of transparency (Folscher and Renzio, 2017). So, OECD must clearly put forth some important legal sanctions directed towards the public financial operations that are actually being delivered understand for citizens. Certainly, in the recently years OECD has taken fiscal decisions such as offering audit and integrity for the parliament and its committees to engage with the budget process at all key stages of the budget cycle. If OECD has urged all member states to be sensitive about complying with these decisions, but anyways these taken decisions aimed at transparency are insufficient whatever being standards of quality and levels of their financial alteration efficiency (Lienert and Jung, 2004). Above all, the lack of an independent legal process can be considered the most important problem of developing countries in the financial process. In short, the healthy operation of the public budget directed towards to ensure fiscal transparency requires a structure that is far from legal and negative impacts. For developing countries, this structure inevitably requires significant radical changes on the basis of legislation. In other words, a developing country without legal reforms is also very weak in terms of fiscal transparency due to require to promote the integrity and quality of budgetary financial forecasts, fiscal plan. Namely, the shortage budgeting and structural incompatibility of financial objectives and strategic plans is the inevitable important problem for financial applications in these countries where financial infrastructure is weak. A broad public funding pool for the provision of fiscal transparency is also the key to an effective public budget implementation for developing countries (NTRSA, 2016). The fact of financial transparency is, 
of course, a much broader concept than being expressed only in this known classical case especially in developing countries.

At the same time, the concerned fiscal transparency should ensure that financial risks of these countries are avoided and financial changes are permanent. Especially in developing countries, it is very important for the sustainability of fiscal transparency to provide financial support to support capital formation in economic growth. On the other hand, it is important that the financial changes in developing countries should be structured in such a way that the public participation of these countries in the budget-constructing process that but it is in condition with far from populist politics. Because, these countries could have different public expectations from government budget due to the different public services and the varying financial contributions of these countries especially for developing countries like Nigeria, which mean to weaker a financial transparency process within its dynamics (Onyiah et al, 2016).

\section{THE FORMATION OF FINANCIAL TRANSPARENCY PROCESS AND EXPECTATIONS FROM DEVELOPING COUNTRIES}

The transparency process in the scope of the budgetary governance advert to clearly review and being understood throughout the applications processes and then in its last. Therefore, the formation of financial transparency process includes some the revised laws, structures altered and financial institutions' alterations in place for ensuring that the budgeting system meets its objectives in an effective, sustainable and enduring manner. All of these are not only the dynamics of the public budget, but the priority goals and dynamites of the fiscal transparency process. And also, the transparency process considers taking account of the extensive financial analysis that has been organized under the backing of the OECD and other national constructing forms and international organizations on affairs relating to budgetary governance (Bastida and Benito, 2007).

\section{The Structural of Financial Transparency Process and Its Purposes}

The primary purpose of transparency dynamics must be ensuring to run after a sound and sustainable fiscal policy in using financial resource funding prudently. This is meaningful from the point of view of formation of financial transparency process having dynamics that put forth a position to support governments in effecting global economic and financial crisis or cyclically neutral policies. Therefore, in the analysis of the economic and financial crises in most of the developing countries, it is considered that the formation of financial transparency sets important criteria with financial standards. This is also the reason why the analysis of public expenditures together with public incomes as the structural transparency dynamics in the formation of the fiscal transparency process should be made clear. Along with that the fiscal transparency process also reveals significant dynamics in monitoring public investments and clarifying budgetary budgets for investments (Anderson and Penner, 2016). The formation of the transparency process should be completed by structuring all expenditure items for public investments as subject to a value matching before and after. From this point of view, the transparency process can be considered to be a clarification of an internal control process as "citizen's budget" or budget summary in a standard format (Williams et al. 2017). The structural framework of fiscal transparency should be addressed in a timing manner consistent with some financial radical changes, and this process should begin with the determination of objectives first. And also, if the radical alterations are not supported via the based public opinion that mean to voluntary social contributions, it is not possible to appear to reach the desired proposals of transparency formation (Williams et al. 2017). Therefore, the formation process related to transparency need more the structural alterations that are based public 
especially in developing countries, which mean to absorb. This process includes also analytical approaches that put forth the transparency problems sufficient to undertake some analyses that are meaningful to improve public responsibility in the assimilated transparency dynamics (Douglas and Meijer, 2016).

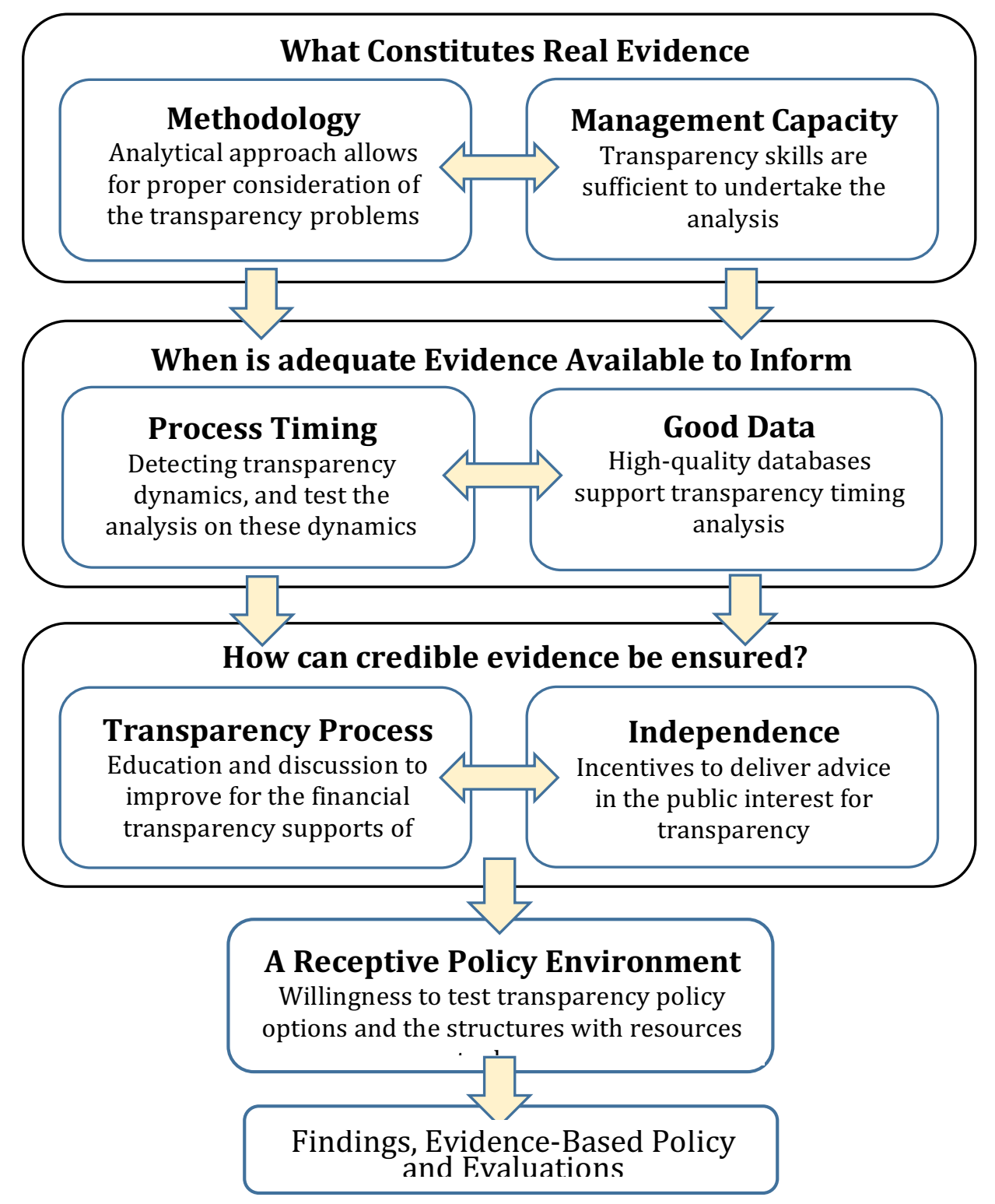

Sources: Australian Public Service Commission (APSC), 2009.

Figure 2. The Formation of Financial Transparency Process

As a process of financial transparency, a different methodology may be needed for all countries. As seen in Figure 2, the process and success of transparency is directly related to the existing structural presence and success of management activities. Because, it is the public decision-making processes that shape the methodology, as related to financial management decisions, have an effect on all the united valuations and common last findings that are handled in this government process. But, it appears that are inevitable some important matters in developing countries that can put forth financial transparency while this concerned process run. This problem in the developing countries can be considered the problem of timing evaluations, as in the recent light of the finds, more than the problem of the methodology as more meaningful matter (Dieffenthaler, 2014). Radical financial changes that support the transparency formation process should be primarily determined due to having inevitably 
argued that an increasing in the excitability of different macroeconomic variables which mean beneficial for financial agents forming expectations for transparency process. The formation of transparency process emphasis to put forth also political transparency that is supported institutional arrangements, and this concepts sense to occur in the operational transparency approaches related to the unanticipated financial disturbances, as helpers to transparency process (Ban and Seabrooke, 2016).

Operational transparency in developing countries, at this stage, is meaningful as a result analysis of the process of transparency, and an important ground for the development of new finance polices for the future. Because all analytical transparency procedures come up with a political implication, as a whole of the transparency process, over the outcome values of the financial transactions directed towards to shape the financial policies in the future. In this context, fiscal transparency must also emphasize financial neutrality in the context of a structural transformation in order to direct national savings. The aim of this approach is to ensure willingness to test transparency and the structures with resources in the formation of transparency process. This process include also reasons to deliver advice in the public interest for transparency that ensure to construction the desired transparency process via public opinion. For developing countries, the timing of financial changes and the need to adjust in time with financial transparency objectives are to meet in these common points that should be addressed to be in common. As this location of the process it can be said that it put forth all the associated financial purposes related to both transparency process and radical structural alterations in developing countries towards to financial consensus together with the other countries (IMF, 2016).

\section{The Recommends in The Transparency Process in the Consolidated Financial Structure}

Some important recommends are inevitable that take place in the transparency process as applying budgetary management with these comprehensible fiscal policy objectives. In other words, to position policies with financial resources for transparency politics of in terms of fiscal horizon should be taken in overall budget targets for each developing countries. In this point, the transparency process should include all elements of revenue together with public expenditure that are considered in financial transparency analyses, and should be in line with the other financial resources for ensuring covering a large economic policy that is consistent.

In recommends terms of a public transparency policy, this structural aim means that a transparency policy should set out the elements of the financial strategies, and that the scope of the financial budget be expressed in net values. But, the evaluation and implementation of a national transparency ground for supporting public investments, which should put forth a range of inevitable proposes factors including (OECD, 2017). First of all, suitable institutional capacity to ensure, and manage various capital projects are required, and this fact is rather important to understand that contribute to ensure the financial contributing in public budget for financial analyses. Second, a stable legal, administrative and regulatory framework should be reliable and suitable in the formation and understand of transparency process. Third, it is expected from the transparency process in the alterations framework is that should support the economic policy coordination of investment projects through national and sub-national levels of government aims directed towards to economic real resources supply. Because, national economic investments and incentives need to extremely clear financial limit values for developing countries. Fourth, expectations from the formation of transparency process should put forth the aimed integration of capital budgeting within the overall medium-term fiscal plan of the government related to public budgets, which is rather meaningful to more need the fiscal transparency process. This recommended objective is to be directed to more opening 
presentation and explanation of the impact of budget measures in especially developing countries. Certainly, the fiscal transparency should contain that make easy to understand this formation process considering verifiable fiscal rules or policy objectives related to the credibility of socio economics that can be enhanced through. Namely, the clear transparency process must predict firstly the government's financial politics process within the harmonization of economic cycle to analyses via the based public opinion. Also, It should not be ignored that the other institutional mechanisms being related to the transparency recommendations are required to provide an independent perspective in this regard. The one of facts that is to be made this concept a current issue is budgetary applying top-down directed towards transparency concept, which mean reorganising and reconstructing the budget allocations in a term of fiscal transparency that correlate readily with national fiscal objectives (World Economic Forum, 2017)

In this respect, the fiscal transparency process in developing countries makes it inevitable for institutional incentives to occur with institutional flexibility. Institutional flexibilities are the indispensable most important dynamics of the fiscal adjustment process, and national facts supported by the fiscal transparency in the structural changes process. The most important financial recommend for the financial transparency process in a developing country is the public view ability of tax revenues. At this stage, it can be said that facts of objective compatibility in terms of fiscal transparency are meaningful, but this fact depends on the condition with harmonization the fiscal expectations and public budget targets for a developing country. As said before, the fiscal transparency process for a developing country makes it absolutely inevitable to consider public expenditures and incomes in a clear consensus structure (World Economic Forum, 2017). An effective decision-making process in the formulation of financial policies should also clarify institutional contributions when monitoring financial transaction documents, and present structural changes with net costs. The public monitoring of the costs of public financial change is undoubtedly significant in bringing public support (Republic of Macedonia Ministry of Finance-RMMF, 2017).

The structural problems of developing countries with weak financial institutions are, at this stage, should be deal with clearly in the suggestion framework that this structural phenomenon must be overcome. Without institutional changes, it is not possible to achieve the desired level of financial transparency and it should not be overlooked that providing institutional change that is an important component directed towards financial transparency goals. In terms of developing countries in the framework of financial expectations and proposals, this phenomenon is a remarkable approach both in terms of a stable public budget and in terms of fiscal transparency (OECD, 2017). Therefore, the fiscal transparency means that ensure budget application sincerity in term of the alteration process and control the use of "off-budget" fiscal mechanisms, which require supplementary financial information is needed in the fiscal transparency in the scope of the recommended financial purposes. Briefly, in related to the political approach the systematically of transparency approach should put forth the setting boundaries for the foremost of expenditure categories for each year of the medium period, but in condition with in terms of fully aligned with the top-down budgetary constraints agreed by government in the application process.

\section{CONCLUSION}

The fact that the financial transparency process recommends different dynamics for each developing country also put forth the institutional details for financial structures. The harmonization between central banks and the public budgets of these countries is often seen as sufficient in terms of a fiscal transparency process. This view is not absolutely valid for every developing country because the development gap of countries often necessitates the 
existence of institutional process alignment in terms of fiscal transparency. The necessity for economic and financial proposals to support institutional changes is born from this point. The two most important factors in ensuring fiscal transparency are, of course, public expenditures and revenues. The transparency process should target structural changes related to them. Without a structural change in institutions, especially in developing countries, it seems quite difficult to achieve fiscal transparency.

And also, apart from the institutional structure, it is also understood that the public has also made a significant contribution to the fiscal transparency process, which should have been to maintain especially in developing countries. The entire process can be described as a radical financial transformation process, and financial transparency is only one of the building blocks that must be overcome. Proposals on fiscal transparency for developing countries in this respect do not arise from unilateral facts and this complex structure would be able to cause the significant institutional deviations in the analysis of public budget in order to correctly analyses in the pure transparency concept. Although all public sector based analyses aim primarily at ensuring fiscal transparency, it is the undeniable reality of developing countries that public financial changes require a new political structure in these countries. This fiscal politics is that mean the government budget policy, as a general financial framework, in developing countries. From this perspective, it appears that primarily the aimed changes that need for a radical change in the public budget application process related to the fiscal transparency process plays a key role in this process.

\section{References}

Alt, J. E. and Lassen, David D. (2003), Fiscal Transparency and Fiscal Policy Outcomes in OECD Countries, Economic Policy Research, Copenhagen: Institution of Economics University of Copenhagen, November 3, 2003.

Anderson, B. and Penner, R. (2016), “Time for a New Budget Concepts Commission”, Economics Studies at Brookings, No. 3, January 2016.

Arnold, P. J. (2011), The Political Economy of Financial Harmonization: The East Asian Crisis and the Rise of International Accounting Standards, Revision February 10, 2011, https://elsevier.conferenceservices.net/resources/247/2182/pdf/CPAC2011_0027_paper.pdf (14.05.2018).

Australian Public Service Commission (APSC) 2009, http://www.apsc.gov.au/publications-andmedia/archive/publications-archive/evidence-based-policy (10.052018).

Ban, C. and Seabrooke, L. (2016), Investing and Integrity: Transparency \& Accountability of The European Investment Bank, Berlin: Transparency International EU Office, 2016.

Benito, B. and Bastida, F. (2007), “Central Government Budget Practices and Transparency: An International Comparison”, Public Administration Review, Vol. 85, Issue: 3, May/June 2007, pp. 667-716.

Benito, B. and Bastida, F. (2009), "Budget Transparency, Fiscal Performance, and Political Turnout: An International Approach”, Public Administration Review, Vol. 69, Issue: 3, May/June 2009, pp. 403-417.

Bird, J. J. (2011), “Dollars and Sense: A Budget-Building Framework of Transparency for Superintendent Leadership”, Management in Education, Vol. 25, Issue: 4, pp. 156-162.

NTRSA, (National Treasury Republic of South Africa) (2016), Budget Review, 24 February 2016.

Carolan, L. (2016), Open Data, Transparency and Accountability: Topic Guide. Birmingham, UK: GSDRC, University of Birmingham, 2016.

Chen, B.L. (2006), "Economic Growth with an Optimal Public Spending Composition", Oxford Economic Papers, 58, 2006, pp. 123-136.

Dieffenthaler, L. (2014), Optimal Central Bank Transparency - Assessing the Holy Grail of Monetary Policy, May 10, 2014, Oslo: Master of Philosophy in Economics Department of Economics University of Oslo, 2014.

Douglas, S. and \& Meijer, A. (2016), Transparency and Public Value: Analyzing the Transparency Practices and Value Creation of Public Utilities, International Journal of Public Administration, Vol. 39, Issue: 12, 2016, pp. 940951. 
Folscher, A. and De Renzio, P. (2017), The Road to Budget Transparency Learning from Country Experience, Washington, D.C.: International Budget Partnership, 2017.

IMF (2016), IMF Annual Report 2016-Finding Solution Together, Washington D.C.: International Monetary Fund, 2016.

Lienert, I. and Jung, M. (2004), “Comparison of OECD Countries' Frameworks for Budget Systems,” in The Legal Framework for Budget Systems: Special Issue, OECD Journal on Budgeting, Vol. 4, Issue: 3, 2004.

OECD (2014), Draft Recommendation of The OECD Council on The Principles of Budgetary Governance on Principles of Budgetary Governance, Public Governance \& Territorial Development Directorate, July 2014.

OECD (2015), Recommendation of The Council on Budgetary Governance, Public Governance \& Territorial Development Directorate, February 2015.

OECD (2017), Budget Transparency Toolkit: Practical steps for supporting openness, integrity and accountability in Public Financial Management, Public Governance Directorate, OECD, 2017.

Onyiah, I. A.; Ezeamama, N. C.; Ugwu, J. N. and Mgbodile, C. C. (2016), “Nigerian Budget Implementation and Control Reforms: Tool for Macro Economic Growth", British Journal of Economics, Management \& Trade, Vol. 11, Issue: 2, 2016, pp. 1-13.

Republic of Macedonia Ministry of Finance-RMMF (2017), Public Financial Management Reform Programme 2018 - 2021, Skopje: Ministry of Finance, September, 2017.

Williamson, V. and Eisen, N. (2016), The Impact of Open Government: Assessing the Evidence, Working Paper, December 2016, Brookings: Center for Effective Public Management, Development Policy Research Unit, December 2016.

Williams, E.; Denny, E. St. and Bristow, D. (2017), Participatory Budgeting: An Evidence Review, Public Policy Institute for Wales, August, 2017.

World Economic Forum-WEF (2017), The Inclusive Growth and Development Report 2017, Geneva: The World Economic Forum, January 2017. 